\title{
Risks of Alcoholic Energy Drinks for Youth
}

\author{
David L. Weldy, $M D, P h D$
}

Ingesting alcohol and energy drinks together is associated with a decreased awareness of the physical and mental impairment caused by the alcohol without reducing the actual impairment. This is of particular concern for youth who have a baseline of less mature judgment. Adding energy drinks to alcohol tends to increase the rate of absorption through its carbonation and dilution of the alcohol, and keep a person awake longer allowing ingestion of a greater volume of alcohol. At low blood alcohol levels, caffeine appears to decrease some of the impairment from the alcohol, but at higher blood alcohol levels, caffeine does not appear to have a modifying effect on either the physical or mental impairment induced by the alcohol. Obtaining this combination is made easier and more affordable for under aged persons by manufacturers of premixed alcoholic energy drink combination beverages. Awareness by medical and educational personnel and parents of this activity and its potential for harm is unknown. (J Am Board Fam Med 2010;23:555-558.)

Keywords: Risk, Alcohol Drinking, Energy Drinks, Drug Abuse, Adolescence, Behavioral Science, Research Letter

The concept of getting someone sober by loading him or her with coffee is a time-honored tradition. The newer activity of ingesting energy drinks that contain alcohol to maintain the feeling of alertness potentially increases the risk of physical and social harm. ${ }^{1,2}$ It gives the perception of decreased intoxication without altering impairment. ${ }^{1,3,4}$ Previously a do-it-yourself activity by college students, ${ }^{5}$ entrepreneurs made it easier for underage individuals by producing premixed drinks, such as Rock Star 21, Joose ${ }^{6}{ }^{\text {and Steel Reserve, }}{ }^{6-9}$ usually by adding vodka, with an alcohol content of $6 \%$ to $9.9 \%$, and caffeine (80 to $400 \mathrm{mg}$ ) to the energy drink. ${ }^{6-9}$

When asked to speak on this topic to a parents' group, I was uneducated. To determine if this was an individual failing, an informal poll of a family medicine department and residency revealed that only just more than one third of the faculty and

This article was externally peer reviewed.

Submitted 20 November 2009; revised 18 March 2010; accepted 25 March 2010.

From the Department of Family Medicine, University of Toledo College of Medicine, OH.

Funding: none.

Conflict of interest: none declared.

Corresponding author: David L. Weldy, MD, PhD, Department of Family Medicine, University of Toledo College of Medicine, 3000 Arlington Avenue, MS 1179, Toledo, OH 43614 (E-mail: david.weldy@utoledo.edu). residents were aware of the use of alcohol in energy drinks.

Carbonated energy drinks such as Red Bull, Monster, and Blast, for example, contain ingredients intended to induce alertness, concentration, and focus. ${ }^{10,11}$ The main stimulant is caffeine in doses of 80 to $400 \mathrm{mg}$, compared with 80 to $175 \mathrm{mg}$ in a cup of coffee. Energy drinks also contain taurine, carbohydrates, glucuronolactone, inositol, niacin, pantanol, and $\mathrm{B}$ vitamins as well as proprietary substances ${ }^{1,11-17}$ and even ethanol. ${ }^{18}$ Caffeine alone is associated with sensation seeking and impulsivity among college students, ${ }^{19}$ including sexual activity, marijuana use, seatbelt omission, taking a dare, smoking, alcohol problems, illicit prescription drug use, and "identity and masculinity behaviors" associated with sports. ${ }^{20,21}$

The above behaviors may be enhanced by consuming alcohol with energy drinks. ${ }^{1,9}$ An association between the heavy use of caffeine and heavy alcohol use was noted as early as $1984 .^{22,23}$ A survey by Malinauskas $^{2}$ of 496 university students revealed that $65 \%$ to $67 \%$ used one energy drink to stay awake because of insufficient sleep and to increase energy, and $54 \%$ commonly used 3 or more energy drinks with alcohol while partying.

Physicians should be familiar with the well-established effects of alcohol, including an artificially increased sense of well-being and competence, pro- 
longed reaction time, and decreased coordination, social inhibition, and judgment. ${ }^{24}$ At higher doses there can be sedation, amnesia, and loss of consciousness, but adding energy drinks to alcohol does several things.

- Carbonation tends to increase the rate of absorption of alcohol. ${ }^{25}$

- Diluted concentrations of alcohol are emptied from the stomach into the faster absorbing small intestine more rapidly than high concentrations. $^{25}$

- Caffeine keeps one awake and blunts the sedative effects of the alcohol. ${ }^{14,26}$

- Lengthened time awake theoretically allows greater alcohol intake before loss of consciousness. ${ }^{14,26}$

- At low blood alcohol levels, caffeine appears to decrease some of the physical and mental impairment from the alcohol. At higher blood alcohol levels caffeine does not appear to have a modifying effect on either the physical or mental impairment induced by the alcohol. ${ }^{26}$

- Energy drink ingredients give the consumer a greater false sense of physical and mental competence and decrease the awareness of impairment. ${ }^{26,27}$

The physiologic and psychological response to alcohol depends on well-known factors, including body weight, sex, sleep status, general health, hepatic health, nutrition, and medication. ${ }^{28}$ Therefore, the quantities of caffeine, alcohol, and other ingredients in alcoholic energy drinks, as well as the ratios needed to produce alertness despite impairment from intoxication, are dependent on the individual and their previous exposure to and tolerance of alcohol and caffeine. ${ }^{11,29,30}$

The final result of the combination of caffeine, carbonation, and alcohol may be a more rapid absorption of alcohol, a greater total volume of alcohol absorbed, greater physical impairment, and a significantly reduced perception of intoxication in oneself as well as others. ${ }^{14,25-27}$ This prevents one from recognizing impairment or risky behavior in others, such as not recognizing that one's driver is drunk, ${ }^{1,3,4,27}$ and may enhance risk-taking behavior $^{1,31}$ by young individuals who are known to have a baseline of less mature judgment concerning sexual activity and motor vehicle use, an increased sense of immortality, and disregard for the risks of pregnancy, sexually transmitted diseases, accidents, and injury. A recent survey of patrons leaving bars showed that those who consumed alcohol with energy drinks had a 3 -fold increased risk of intoxication and a 4-fold increased intent to drive compared with those ingesting only alcohol. ${ }^{31}$ There is also concern for precipitating sudden cardiac arrhythmia in individuals with an arrhythmogenic predisposition. $^{32}$

Alcohol ingestion and subsequent risk-taking behavior may be further enabled by marketing strategies that make it easier for youth to obtain alcohol and hide alcohol use. ${ }^{9,33}$ The packaging of the combination drinks is nearly identical to energy drinks without alcohol, resulting in the sale of these products to minors or unsuspecting parents., $33-35$ Because the Food and Drug Administration previously determined that these products were adequately labeled as alcoholic beverages, they could be placed next to plain energy drinks in areas of a store that are not necessarily associated with alcohol. ${ }^{36,37}$ The Food and Drug Administration controls and requires drinks with less than $7 \%$ alcohol content to have all ingredients listed on the label (reference 38 and FDA Public Affairs Specialist 9, personal communication). Previously, drinks with an alcohol content of $7 \%$ or greater were controlled by the Bureau of Alcohol, Tobacco, and Firearms, which did not require labeling other than the alcohol content, which was often in fine print. ${ }^{39}$ These drinks with higher alcohol content are now regulated by the Division of Alcohol Tobacco Tax and Trade Bureau. Some alcohol-laced beverages have been priced lower than similarly packaged, nonalcoholic energy drinks, ${ }^{9,33}$ and they are certainly less expensive than purchasing energy drinks and alcohol separately. Although most studies to date have been on college-age adults, the association of energy drink use with increased alcohol problems ${ }^{20}$ raises concern for younger individuals who consume energy drinks as early as 12 years old. ${ }^{9}$ The Simmons Teen Survey revealed that $28 \%$ of 12 - to 14 -year-olds, $31 \%$ of 12 - to 17 -year-olds, and $34 \%$ of 18 - to $24-$ year-olds consumed energy drinks regularly. ${ }^{9,20}$ Sparks (Steel Brewing Co., Milwaukee, WI) and Spykes (Anheuser-Busch, St. Louis, MO) have been withdrawn from the market, and caffeine and other stimulants have been removed from Tilt and Bud Extra (Anheuser-Busch) after several states' Attorneys General alleged inac- 
curate labeling of alcohol content and marketing to minors. ${ }^{6,40-42}$

The awareness among the medical community of the use of alcohol with energy drinks is unknown. This should be studied further, and efforts should be made to identify at-risk children and youth. A screening question about energy drink use as well as alcohol and caffeine use added to a patient's social history may be an indicator of other substance use and/or risky behavior. ${ }^{20}$ Efforts to educate students, parents, families, schools, communities, medical students, residents, and practicing physicians should be established. Further research is needed about how education is best done and if presentations by physicians (especially team physicians) or ancillary personnel to parent organizations, educators, and school personnel improves awareness and detection of signs children are using alcohol and energy drinks together.

\section{References}

1. O'Brien MC, McCoy TP, Rhodes SD, Wagoner A, Wolfson M. Caffeinated cocktails: energy drink consumption, high-risk drinking, and alcohol-related consequences among college students. Acad Emerg Med 2008;15:453-60.

2. Malinauskas BM, Aeby VG, Overton RF, CarpenterAeby T, Barber-Heidal K. A survey of energy drink consumption patterns among college students. Nutr J 2007;6:35.

3. Hadjicharalambous M, Georgiades E, Kilduff LP, Turner AP, Tsofliou F, Pitsiladis YP. Influence of caffeine on perception of effort, metabolism and exercise performance following a high-fat meal. J Sports Sci 2006;24:875-87.

4. Marczinski CA, Fillmore MT. Clubgoers and their trendy cocktails: implications of mixing caffeine into alcohol on information processing and subjective reports of intoxication. Exp Clin Psychopharmacol 2006;14:450-8.

5. Allwood M. A little vodka in your ginseng? New energy drinks come with a kick. Columbia News Service. Available at http://www.vapta.org/library-forms-adocuments/doc_download/849-energy-drink-resolution-2009-national-submission.html. Accessed 25 May 2010.

6. King T, Rowe SG, Goddard T, et al. Sparks brand alcoholic energy drinks. Available at http://www. oag.state.md.us/Press/sparks.pdf. Accessed 28 February 2010.

7. Food and Drug Administration. List of manufacturers of caffeinated alcoholic beverages. Available at http://www.fda.gov/Food/FoodIngredientsPackaging/ ucm190448.htm. Accessed 14 November 2009.

8. AlcoholContents.com. Beer calories, carbs, and alco- hol content. 2008 Available at http://www.alcohol contents.com/beer/beer.htm. Accessed 12 January 2010.

9. Simon M, Mosher J, Marin Institute. Alcohol, energy drinks, and youth: a dangerous mix. 2007. Available at http://www.marininstitute.org/alcopops/ resources/EnergyDrinkReport.pdf. Accessed 27 February 2010.

10. Dugdale DC. Caffeine in the diet. 2009. Available at http://www.nlm.nih.gov/medlineplus/ency/article/ 002445.htm. Accessed 15 February 2010.

11. Babu KM, Church RJ, Lewander WL. Energy drinks: the new eye-opener for adolescents. Clin Ped Emerg Med 2008;9:35-42.

12. Ferreira SE, de Mello MT, Rossi MV, Souza-Formigoni ML. Does an energy drink modify the effects of alcohol in a maximal effort test? Alcohol Clin Exp Res 2005;28:1408-12.

13. Ferreira SE, Hartmann Quadros IM, Trindade AA, Takahashi S, Koyama RG, Souza-Formigoni ML. Can energy drinks reduce the depressor effect of ethanol? An experimental study in mice. Physiol Behav 2004;82:841-7.

14. Oteri A, Salvo F, Caputi AP, Calapai G. Intake of energy drinks in association with alcoholic beverages in a cohort of students of the School of Medicine of the University of Messina. Alcohol Clin Exp Res 2007;31:1677-80.

15. Energyfiend.com. Energy drink ingredients. 2008. [Comments.] Available at http://www.energyfiend. com/energy-drink-ingredients/comment-page-5\# comments. Accessed 12 February 2010.

16. Curry K, Stasio MJ. The effects of energy drinks alone and with alcohol on neuropsychological functioning. Hum Psychopharmacol 2009;24:473-81.

17. McCusker RR, Goldberger BA, Cone EJ. Caffeine content of energy drinks, carbonated sodas, and other beverages. J Anal Toxicol 2006;30:112-4.

18. Lutmer B, Zurfluh C, Long C. Potential effect of alcohol content in energy drinks on breath alcohol testing. J Anal Toxicol 2009;33:167-9.

19. Jones HA, Lejuez CW. Personality correlates of caffeine dependence: the role of sensation seeking, impulsivity, and risk taking. Exp Clin Psychopharmacol 2005;13:259-66.

20. Miller KE. Energy drinks, race, and problem behaviors among college students. J Adolesc Health 2008; 43:490-7.

21. Miller KE. Wired: energy drinks, jock identity, masculine norms, and risk taking. J Am Coll Health 2008;56:481-9.

22. Istvan J, Matarazzo JD. Tobacco, alcohol, and caffeine use: a review of their interrelationships. Psychol Bull 1984;95:301-26.

23. Kozlowski LT, Henningfield JE, Keenan RM, et al. Patterns of alcohol, cigarette, and caffeine and other drug use in two drug abusing populations. J Subst Abuse Treat 1993;10:171-9. 
24. Marczinski CA, Fillmore MT. Acute alcohol tolerance on subjective intoxication and simulated driving performance in binge drinkers. Psychol Addict Behav 2009;23:238-47.

25. Roberts C, Robinson SP. Alcohol concentration and carbonation of drinks: the effect on blood alcohol levels. J Forensic Leg Med 2007;14:398-405.

26. Liguori A, Robinson JH. Caffeine antagonism of alcohol-induced driving impairment. Drug Alcohol Depend 2001;63:123-9.

27. Ferreira SE, de Mello MT, Pompeia S, de SouzaFormigoni ML. Effects of energy drink ingestion on alcohol intoxication. Alcohol Clin Exp Res 2006;30: $598-605$.

28. Fillmore MT, Marczinski CA, Bowman AM. Acute tolerance to alcohol effects on inhibitory and activational mechanisms of behavioral control. J Stud Alcohol 2005;66:663-72.

29. Fillmore MT. Alcohol tolerance in humans is enhanced by prior caffeine antagonism of alcohol-induced impairment. Exp Clin Psychopharmacol 2003; 11:9-17.

30. Reissig CJ, Strain EC, Griffiths RR. Caffeinated energy drinks-a growing problem. Drug Alcohol Depend 2009;99(1-3):1-10.

31. Thombs DL, O'Mara RJ, Tsukamoto M, et al. Event-level analyses of energy drink consumption and alcohol intoxication in bar patrons. Addict Behav 2010;35:325-30.

32. Wiklund U, Karlsson M, Ostrom M, Messner T. Influence of energy drinks and alcohol on post-exercise heart rate recovery and heart rate variability. Clin Physiol Funct Imaging 2009;29:74-80.

33. Hicks D, O'Connor T, Ventura County Behavioral Health Department. Alcohol energy drinks: a dangerous mix. 2007. Available at http://www.ventra countylimits.org/pdfs/alcohol_energy_drinks_dec07. pdf. Accessed 12 February 2010.
34. Erb R. Energy drinks with alcohol stir fears. Toledo Blade. August 13, 2007.

35. Clerks cited for selling alcoholic energy drinks. Cincinnati: E.W. Scripps Co; 2007. Available at http:// www.kypost.com/content/wcposhared/story/ClerksInadvertently-Selling-Alcohol-To-Minors/uviEqOM NyE626C9hoDEBzQ.cspx. Accessed 27 February 2010.

36. Rose J. Alcoholic energy drinks causing confusion. KCPW News; 2007. (No longer available online).

37. Peterson M, Public Health Newswire. Utah county health advocates alcohol placement laws. 2007. Available at http://phn.ctlbyu.org/?p=20. Accessed 27 February 2010.

38. Food and Drug Administration. What the FDA doesn't regulate. 2009. Available at http://www.fda. gov/AboutFDA/WhatWeDo/WhatFDADoesnt Regulate/default.htm. Accessed 25 May 2010.

39. Lopez J, Dupre V. The energy drink revolution: energy drinks 103: through the looking glass into your community. Fallbrook, CA: The Village News Inc. 2008. Available at http://www.thevillagenews. com/story.php?story\%20id=28262. Accessed 27 February 2010.

40. Gardner S, Center for Science in the Public Interest. State Attorneys General negotiate end of caffeinated "Sparks" beer. 2008. Available at http://www. cspinet.org/new/200812182.html. Accessed 27 February 2010.

41. Joley LA. Assurance of voluntary compliance and voluntary discontinuance. Available at http://www. oag.state.md.us/Reports/A-B\%20AVC\%20Final.pdf. Accessed 28 February 2010.

42. Mariani J. Anheuser-Busch to take caffeine out of Tilt, Bud Extra. Syracuse: The Post-Standard. 2008. Available at http://www.syracuse.com/news/index. ssf/2008/06/anheuserbusch_to_stop_selling.html. Accessed 27 February 2010. 